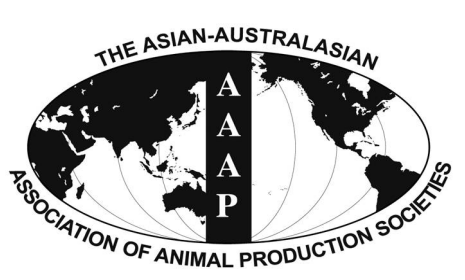

Open Access

Asian Australas. J. Anim. Sci.

Vol. 28, No. 10 : 1471-1478 October 2015

http://dx.doi.org/10.5713/ajas.15.0245

www.ajas.info

pISSN 1011-2367 elSSN 1976-5517

\title{
Feeding of Dehulled-micronized Faba Bean (Vicia faba var. minor) as Substitute for Soybean Meal in Guinea Fowl Broilers: Effect on Productive Performance and Meat Quality
}

\author{
Vincenzo Tufarelli* and Vito Laudadio \\ Department of Emergency and Organ Transplantation, Section of Veterinary Science and Animal Production, \\ University of Bari Aldo Moro, 70010 Valenzano, Bari, Italy
}

\begin{abstract}
The present study aimed to assess the effect of dietary substitution of soybean meal (SBM) with dehulled-micronized faba bean (Vicia faba var. minor) in guinea fowl broilers on their growth traits, carcass quality, and meat fatty acids composition. In this trial, 120 day-old guinea fowl keets were randomly assigned to two treatments which were fed from hatch to 12 weeks of age. Birds were fed two wheat middlings-based diets comprising of a control treatment which contained SBM (78.3 g/ $/ \mathrm{kg})$ and a test diet containing dehulled-micronized faba bean $(130 \mathrm{~g} / \mathrm{kg})$ as the main protein source. Substituting SBM with faba bean had no adverse effect on growth traits, dressing percentage, or breast and thigh muscles relative weight of the guinea fowls. Conversely, a decrease $(p<0.05)$ of abdominal fat was found in guinea fowls fed the faba bean-diet. Breast muscle of birds fed faba bean had higher $L^{*} \operatorname{score}(\mathrm{p}<0.05)$ and water-holding capacity $(\mathrm{p}<0.05)$ than the SBM control diet. Meat from guinea fowls fed faba bean had less total lipids $(\mathrm{p}<0.05)$ and cholesterol $(p<0.01)$, and higher concentrations of phospholipids $(p<0.01)$. Feeding faba bean increased polyunsaturated fatty acid concentrations in breast meat and decreased the saturated fatty acid levels. Moreover, dietary faba bean improved the atherogenic and thrombogenic indexes in guinea fowl breast meat. Results indicated that substitution of SBM with faba bean meal in guinea fowl diet can improve carcass qualitative traits, enhancing also meat lipid profile without negatively affecting growth performance. (Key Words: Carcass, Dehulled-micronized Faba Bean, Growth, Guinea Fowl, Breast Meat Quality)
\end{abstract}

\section{INTRODUCTION}

The consumption of all meat-types is decreasing with the exception of poultry meat, which has increased by $80 \%$ in the last three decades, and this trend has stimulated interest in improving the poultry meat (Puvača et al., 2014). Enriched poultry products can therefore serve as vehicle for supplying nutrients such as the omega-3 fatty acids (FAs) whose human consumption is below recommendations (Laudadio et al., 2012). Modifications of poultry product quality through manipulation of their diet and rearing conditions have been reported (Khan et al., 2012; Dhama et al., 2015). These changes also include enrichment of

\footnotetext{
* Corresponding Author: Vincenzo Tufarelli. Tel: +39-080-4679916, Fax: +39-080-467-9916, E-mail: vincenzo.tufarelli@uniba.it Submitted Mar. 20, 2015; Revised Jun. 5, 2015; Accepted Jun. 10, 2015
}

poultry products with health-promoting substances which have been reported to contain anticarcinogenic properties and reduce plasma cholesterol (Laudadio et al., 2015). While the enrichment of broiler meat with nutrients that confer health-promoting properties has been extensively researched, there are few data related to alternative poultry species, such as the guinea fowl. Guinea fowl production for meat is a potentially advantageous enterprise in many parts of the world (Nahashon et al., 2005; Tufarelli et al., 2007). Guinea fowl meat, as alternative meat to chicken, has already proven to be a profitable activity in United States, Canada and also in European markets such as France and Italy (Tufarelli et al., 2007; Laudadio et al., 2012). However, there still remains a challenge in profitability emanating from increasing cost of production which is primarily due to feeding costs. Price variations on feedstuffs market, the growing cost of conventional feeds such as corn 
and soybean meal (SBM) due to their increased demand in the biofuels industry and the increasing demand for alternative poultry justifies the need for less-conventional and locally cultivated feed ingredients.

The SBM is the most widely used protein source in poultry formulations. Nevertheless, when SBM price increases, poultry nutritionists seek alternative protein sources that are more economical in formulating least cost rations. Faba bean (Vicia faba L.) is considered an interesting ingredient in diets of non-ruminant species such poultry (Dal Bosco et al., 2013). Moreover, faba bean contains significant amounts of protein and energy, and its amino acids content is nearly comparable to SBM (Fru-Nji et al., 2007). The inclusion of a high amount of raw faba bean in diets has been reported to have a detrimental effect on productive performance of broilers and laying hens (Diaz et al., 2006). This was attributed to the presence in legume seeds of a variety of biologically active compounds usually referred to as antinutritional factors (Laudadio et al., 2011). Thus, the effects of the antinutritional factors limit the use of raw legumes although various processing techniques tend to decrease the level of antinutritional factors of seed while increasing the protein content (Khattab et al., 2009; Laudadio et al., 2011).

In legume seeds, previous studies reported that heat processing such as micronization increases the digestible nutrients available to birds, resulting in enhanced productive performances (Laudadio et al., 2011). Moreover, hulls removal from legume seeds increased the levels of nutrients for broilers to concentrations comparable with SBM (Medugu et al., 2011). Our earlier studies indicated that dehulled-micronized legumes, pea seeds, are suitable for inclusion in the diets of broiler chickens and laying hens (Laudadio and Tufarelli, 2011; Laudadio and Tufarelli, 2012). Nevertheless, to date little attention has been given to the assessment of the effect of processed legume seeds in guinea fowls diet. Therefore, the scope of this trial was twofold: to assess the effect of substitution of SBM with dehulled-micronized faba bean in diets of guinea fowl broilers on their growth parameters; and to evaluate the influence of feeding dehulled-micronized faba bean on profiles of health-promoting substances in guinea fowl meat.

\section{MATERIALS AND METHODS}

\section{Birds and management}

The present trial was conducted in a commercial poultry facility located in the Bari Province, Italy, and involved a total of 120 1-d-old female guinea fowl broilers obtained from a commercial hatchery, and raised in a conventional controlled environment house. Guinea fowls were individually weighed (average body weight $[\mathrm{BW}] \pm$ standard deviation: $23.4 \pm 0.25 \mathrm{~g}$ ) and randomly assigned to 12 concrete floor pens covered with wood shavings. Each pen housed 10 birds and was equipped with a pan feeder and a manual drinker. Birds were reared under standard brooding and rearing conditions and were provided $23 \mathrm{~h}$ light: $1 \mathrm{~h}$ darkness throughout the feeding period.

The present research was conducted observing the animal welfare Legislative Decree 116/92, Council Directive 98/58/EC, received in Italy by Legislative Decree $146 / 2001$, and Council Directive 2007/43/CE, received in Italy by governmental Decree $181 / 2010$ and Legislative Decree 267/2003.

\section{Feed ingredients preparation}

The evaluated dietary protein sources were: SBM (48\% crude protein $[\mathrm{CP}]$ ) and micronized-dehulled faba bean (Vicia faba var. minor cv. Prothabat), $36 \% \mathrm{CP}$ and $2.6 \%$ of crude fiber, as previously reported by Laudadio et al. (2011). The major grain energy source for both diets, wheat middlings, was obtained from durum wheat (Triticum durum Desf. cv. Appulo). The wheat middlings were previously sieved to separate the fibrous components in order to obtain a product with average crude fiber content $\sim 3 \%$ (Laudadio and Tufarelli, 2011). Faba bean seeds, locally and organically grown, were tempered overnight to the preferred moisture content as recommended by Khattab et al. (2009) using distilled water. Tempered seeds were heated up to $130^{\circ} \mathrm{C}$ using a small experimental bench-top micronizer composed of a tubular quartz infrared lamp (115 V) with a tungsten wire filament enclosed in a ceramic casing (Research Inc., Eden Prairie, MN, USA). Pea processing times were $1.5 \mathrm{~min}$. Dehulling was accomplished with the aid of a roller mill and hulls were separated from cotyledons by air classification. Ingredient and chemical composition of the diets are reported in Table 1.

\section{Dietary treatments}

Guinea fowl broilers were fed two experimental diets, a wheat middling-SBM (control) and wheat middlingmicronized-dehulled faba bean meal, for $84 \mathrm{~d}$. Each dietary treatment was replicated six times, with each replicate comprising one pen of 10 birds. The diets were isocaloric and isonitrogenous containing $18.5 \% \mathrm{CP}$ and $13.0 \mathrm{MJ}$ of $\mathrm{ME} / \mathrm{kg}$ of diet (Table 1), designed to meet or exceed the bird's requirements (Larbier and Leclercq, 1994). Feed (mash form) and water were provided ad libitum throughout the whole feeding trial. The BW and average daily feed intake (ADFI), from which average daily gain (ADG) and feed efficiency were calculated, were measured. Birds' mortality rate was recorded as it occurred.

\section{Sample collection}

A total of three guinea fowls of average BW were 
Table 1. Ingredients and chemical composition of diets fed to guinea fowl broilers

\begin{tabular}{|c|c|c|}
\hline \multirow{2}{*}{ Variable } & \multicolumn{2}{|c|}{ Diet } \\
\hline & Soybean & Faba bean \\
\hline \multicolumn{3}{|l|}{ Ingredients $(\mathrm{g} / \mathrm{kg})$} \\
\hline Wheat middlings ${ }^{1}$ & 860.5 & 811.0 \\
\hline Soybean meal (48\% CP) & 78.3 & - \\
\hline Faba bean meal ${ }^{2}(36 \% \mathrm{CP})$ & - & 130.0 \\
\hline Sunflower oil & 20.0 & 20.0 \\
\hline Dicalcium phosphate & 16.0 & 12.0 \\
\hline Calcium carbonate & 10.0 & 13.0 \\
\hline L-Lys HCl & 5.0 & 4.5 \\
\hline Vitamin-mineral premix ${ }^{3}$ & 2.5 & 2.5 \\
\hline L-Thr & 2.5 & 1.5 \\
\hline Sodium chloride & 2.0 & 2.0 \\
\hline Sodium bicarbonate & 2.0 & 2.0 \\
\hline DL-Met & 1.2 & 1.5 \\
\hline \multicolumn{3}{|l|}{ Chemical analysis $(\%)$} \\
\hline $\mathrm{DM}$ & 89.54 & 89.50 \\
\hline $\mathrm{CP}$ & 18.46 & 18.49 \\
\hline Lipid & 5.04 & 5.01 \\
\hline Crude fibre & 3.52 & 3.27 \\
\hline Ash & 5.52 & 5.44 \\
\hline \multicolumn{3}{|l|}{ Calculated analysis } \\
\hline $\mathrm{ME}(\mathrm{MJ} / \mathrm{kg})$ & 13.07 & 13.05 \\
\hline Lys $(\%)$ & 0.97 & 0.96 \\
\hline $\mathrm{Ca}(\%)$ & 1.00 & 1.00 \\
\hline Total P (\%) & 0.73 & 0.71 \\
\hline Available P (\%) & 0.39 & 0.37 \\
\hline Met+Cys (\%) & 0.75 & 0.74 \\
\hline $\operatorname{Thr}(\%)$ & 0.74 & 0.73 \\
\hline \multicolumn{3}{|l|}{ Fatty acids ${ }^{4}(\%)$} \\
\hline$\Sigma$ SFA & 33.45 & 29.09 \\
\hline$\Sigma$ MUFA & 32.28 & 31.04 \\
\hline ¿PUFA & 34.27 & 39.87 \\
\hline Total n-6 & 32.02 & 36.46 \\
\hline Total n-3 & 1.47 & 2.01 \\
\hline \multicolumn{3}{|l|}{ Anti-nutritional factors ${ }^{4}(\%)$} \\
\hline Vicine & - & 0.05 \\
\hline Convicine & - & 0.02 \\
\hline
\end{tabular}

CP, crude protein; DM, dry matter; ME, metabolizable energy; SFA, saturated fatty acid; MUFA, monounsaturated fatty acid; PUFA, polyunsaturated fatty acid.

${ }^{1}$ Low-fiber wheat middlings obtained from durum wheat (Triticum durum Desf. cv. Appulo; Laudadio and Tufarelli, 2011).

${ }^{2}$ Faba bean meal obtained from dehulled and micronised seeds (Vicia faba var. minor).

${ }^{3}$ Supplied per kilogram of diet: vitamin A 12,500 IU; vitamin E $10 \mathrm{mg}$; vitamin D 2,200 IU; niacin $35.0 \mathrm{mg}$; d-pantothenic acid $12 \mathrm{mg}$; riboflavin $3.63 \mathrm{mg}$; pyridoxine $3.5 \mathrm{mg}$; thiamine $2.4 \mathrm{mg}$; folic acid 1.4 $\mathrm{mg}$; biotin $0.15 \mathrm{mg}$; vitamin B $0.03 \mathrm{mg}$; Mn $60 \mathrm{mg}$; Zn $40 \mathrm{mg}$; Fe 1,280 $\mathrm{mg}$; Cu $8 \mathrm{mg}$; I $0.3 \mathrm{mg}$; Se $0.2 \mathrm{mg}$.

${ }^{4}$ Analyzed.

randomly selected on $\mathrm{d} 84$ of the trial from each pen replicate following a 12-h fasting period, individually weighed and killed by cervical dislocation, and then were immediately bled. The abdominal fat (consisting of fat surrounding the gizzard, proventriculus and in abdominal body cavity), breast (Pectoralis major), and drumstick (Peroneous longus) muscles were removed and weighed. Breast muscles were immediately stored at $-80^{\circ} \mathrm{C}$ for determining lipids content, and others were individually stored in plastic bags at $4{ }^{\circ} \mathrm{C}$ for meat qualitative analysis (Laudadio et al., 2009).

\section{Meat quality analyses}

Meat $\mathrm{pH}$, color and drip loss: At $24 \mathrm{~h}$ after killing, the breast muscle $\mathrm{pH}$ was assessed at $2.0 \mathrm{~cm}$ depth below the surface using a combined glass-penetrating electrode (Ingold, Mettler Toledo, Greifensee, Switzerland). Color measurements were determined on carcass surface over the breast muscles and on a freshly exposed cut surface. A Minolta CR-300 chromameter (Minolta, Osaka, Japan) was set to the $L^{*}$ (lightness), $a^{*}$ (redness), and $b^{*}$ (yellowness) Commission Internationale de l'Eclairage scale (Combes et al., 2008). Drip loss was measured by the filter paper method as reported by Kauffman et al. (1986).

Water-holding capacity: Breast meat water-holding capacity (WHC) was measured after killing according to Sun and Luo (1993). A 0.5 g breast muscle sample was pressed onto an ovendried Whatman 125-mm filter paper (Maidstone, Kent, UK) at 207 bar. The value of WHC was calculated as the ratio of the area of expressed water to the area of the pressed meat sample as measured with a planimeter (model 4236, Keuffel and Esser, Hoboken, NJ, USA).

Chemical analysis: Samples of meat were analyzed for moisture (method 945.15), ash (967.05) and CP (990.03) by oven, muffle furnace and Kjeldahl methods, respectively (AOAC, 2000). Total lipids were extracted according to the method of Folch et al. (1957). Meat total phospholipid and cholesterol levels were determined using the methods described by Bartlett (1959) and Sperry and Webb (1950), respectively.

Fatty acid composition: In preparation for FA composition analysis, samples of diets and breast meat (5 g each) were freeze-dried and then ground. Briefly, methyl heptadecanoate (no. 51633, Fluka, St. Louis, MO, USA) was dissolved into $\mathrm{n}$-hexane $(1 \mathrm{mg} / \mathrm{mL})$ as an internal standard. Methyl esters of the FA were prepared (Sukhija and Palmquist, 1988); samples (300 mg each) and $5 \mathrm{~mL}$ of internal standard were incubated $\left(2 \mathrm{~h}\right.$ at $\left.80^{\circ} \mathrm{C}\right)$ with methanolic acetyl chloride in a total volume of $9 \mathrm{~mL}$. After cooling to room temperature, $7 \mathrm{~mL}$ of $7 \%$ (wt/vol) $\mathrm{K}_{2} \mathrm{CO}_{3}$ was added with mixing, and then the organic phase was collected after centrifuging at $1,500 \times \mathrm{g}$ for $2 \mathrm{~min}$ at $4^{\circ} \mathrm{C}$. The FA methyl esters were fractionated over a CP-SIL883 column $(100 \mathrm{~m} \times 0.25 \mathrm{~mm}$ i.d., film thickness $0.20-\mu \mathrm{m}$ fused 
silica; Varian, Palo Alto, CA, USA) in a Shimadzu (model 2GC17A, Shimadzu, Kyoto, Japan) gas chromatograph with a Hewlett-Packard HP 6890 gas system (Palo Alto, USA) and using flame ionization detection. Helium was used as the carrier gas at a constant flow rate of $1.7 \mathrm{~mL} / \mathrm{min}$. The oven temperature was programmed as follows: $175^{\circ} \mathrm{C}$, held for $4 \mathrm{~min}$; 175 to $250^{\circ} \mathrm{C}$ at $3^{\circ} \mathrm{C} / \mathrm{min}$; and then maintained for $20 \mathrm{~min}$. The injector port and detector temperature was $250^{\circ} \mathrm{C}$. Samples $(1 \mu \mathrm{L})$ were injected by an auto-sampler. Output signals were identified and quantified from the retention times and peak areas of known calibration standards. Composition was expressed as percentages of the total FA.

The saturation (S/P), atherogenic (AI) and thrombogenic (TI) indexes were calculated according to Ulbricht and Southgate (1991) and the hypocholesterolemic/hypercholesterolemic ratio $(\mathrm{HH})$ was calculated, as suggested by Santos-Silva et al. (2002), as follows:

$$
\mathrm{S} / \mathrm{P}=(\mathrm{C} 14: 0+\mathrm{C} 16: 0+\mathrm{C} 18: 0) / \Sigma \mathrm{MUFA}+\Sigma \mathrm{PUFA}
$$

$$
\begin{aligned}
\mathrm{AI}= & (\mathrm{C} 12: 0+4 \times \mathrm{C} 14: 0+\mathrm{C} 16: 0) \\
& /[\Sigma \mathrm{MUFA}+\Sigma(\mathrm{n}-6)+\Sigma(\mathrm{n}-3)] \\
\mathrm{TI}= & (\mathrm{C} 14: 0+C 16: 0+\mathrm{C} 18: 0) \\
& /[0.5 \times \Sigma M U F A+0.5 \times \Sigma(\mathrm{n}-6)+3 \times \Sigma(\mathrm{n}-3)+\Sigma(\mathrm{n}-3) \\
& / \Sigma(\mathrm{n}-6)]
\end{aligned}
$$

$$
\begin{aligned}
\mathrm{HH}=[ & {[(\mathrm{C} 18: 1 \mathrm{n}-9+\mathrm{C} 18: 2 \mathrm{n}-6+\mathrm{C} 20: 4 \mathrm{n}-6} \\
& +\mathrm{C} 18: 3 \mathrm{n}-3+\mathrm{C} 20: 5 \mathrm{n}-3+\mathrm{C} 22: 5 \mathrm{n}-3 \\
& +\mathrm{C} 22: 6 \mathrm{n}-3) /(\mathrm{C} 14: 0+\mathrm{C} 16: 0)]
\end{aligned}
$$

where: MUFA $=$ monounsaturated FA and PUFA $=$ polyunsaturated FA.

\section{Statistical analysis}

Data were analyzed using the analysis of variance option of the General Linear Model of SAS/STAT software (SAS Institute Inc., 2004). The statistical model used was: $\mathrm{Y}_{\mathrm{ijk}}=\mu+\mathrm{P}_{\mathrm{i}}+\mathrm{R}_{\mathrm{ij}}+\gamma_{\mathrm{ijk}}$, where $\mathrm{Y}_{\mathrm{ijk}}=$ response variables from each individual replication or pen, $\mu=$ the overall mean; $\mathrm{P}_{\mathrm{i}}$ $=$ the effect of dietary protein source; $\mathrm{R}_{\mathrm{ij}}=$ the interexperimental unit (replications) error term; and $\gamma_{\mathrm{ijk}}=$ the intra-experimental unit error term. When there was a significant $F$-value means were compared by the StudentNewman-Keuls method. Unless stated otherwise, the significance implies $\mathrm{p}<0.05$.

\section{RESULTS}

Dietary protein source had no effect on guinea fowl broilers growth performance (Table 2). Mean differences in
Table 2. Effect of dietary protein source on growth performance of guinea fowl broilers during the first 12 weeks of growth

\begin{tabular}{lcccc}
\hline \multirow{2}{*}{ Item } & \multicolumn{4}{c}{ Diet } \\
\cline { 2 - 5 } & Soybean & Faba bean & SEM & p-value \\
\hline Initial BW & 23.40 & 23.54 & 0.29 & 0.625 \\
Final BW (g) & 1,966 & 1,977 & 38.82 & 0.442 \\
ADG (g) & 23.4 & 23.5 & 0.22 & 0.547 \\
ADFI (g) & 65.7 & 65.2 & 0.49 & 0.337 \\
Feed efficiency (g/g) & 2.81 & 2.78 & 0.08 & 0.109 \\
Mortality (\%) & 1.1 & 1.0 & 0.05 & 0.692
\end{tabular}

SEM, standard error of the mean; BW, body weight; ADG, average daily weight gain; ADFI, average daily feed intake.

BW, ADG, ADFI and feed efficiency of the birds fed the SBM-based diet were not different from those fed the dehulled-micronized faba bean meal diet. Similarly, mean mortality rate was low and was not different between the two treatments $(\sim 1.0 \%)$. Eviscerated carcass yield, determined after the removal of the head, neck, and feet, was approximately $69.5 \%$ in both groups and it was also not different between the two dietary treatments (Table 3). Further, the breast and thigh plus drumstick yields were similar between the treatment groups. However, a decrease $(\mathrm{p}<0.05)$ in abdominal fat pad content was found in guinea fowls fed faba bean-based diet when compared to SBMbased diet (1.33\% vs $1.88 \%$, respectively). Breast meat $\mathrm{pH}$ was not different among the dietary treatment groups. While differences in meat drip loss, protein or ash percentage of guinea fowl broilers fed either of the two dietary treatments

Table 3. Effect of dietary protein source on carcass yield and breast meat quality parameters of guinea fowl broilers at 12 weeks of age

\begin{tabular}{lcccc}
\hline \multirow{2}{*}{ Item } & \multicolumn{4}{c}{ Diet } \\
\cline { 2 - 5 } & Soybean & Faba bean & SEM & p-value \\
\hline Carcass traits & & & & \\
Eviscerated carcass & 69.3 & 69.5 & 0.19 & 0.396 \\
Breast & 23.4 & 23.1 & 0.12 & 0.401 \\
Thigh and drumstick & 22.5 & 22.8 & 0.10 & 0.091 \\
Abdominal fat & 1.88 & 1.33 & 0.06 & $<0.05$ \\
Meat parameters & & & & \\
$\mathrm{pH}_{24}^{2}$ & 5.72 & 5.69 & 0.04 & 0.274 \\
$L^{*}$ (lightness) & 47.03 & 49.01 & 0.57 & $<0.05$ \\
$a^{*}$ (redness) & 16.15 & 16.55 & 0.66 & 0.066 \\
$b^{*}$ (yellowness) & 5.74 & 5.87 & 0.23 & 0.203 \\
WHC (\%) & 61.47 & 62.89 & 0.31 & $<0.05$ \\
Drip loss (\%) & 1.52 & 1.48 & 0.08 & 0.101 \\
Moisture (\%) & 73.25 & 73.11 & 0.44 & 0.126 \\
Protein (\%) & 23.62 & 23.55 & 0.24 & 0.288 \\
Fat (\%) & 1.84 & 2.09 & 0.10 & $<0.05$ \\
Ash (\%) & 1.29 & 1.25 & 0.05 & 0.303 \\
\hline
\end{tabular}

SEM, standard error of the mean; WHC, water-holding capacity.

${ }^{1}$ Percentage of body weight at slaughter.

${ }^{2} \mathrm{pH}_{24}, \mathrm{pH}$ at $24 \mathrm{~h}$ postmortem. 
were not significant, guinea fowls fed the treated faba beanbased diet showed an increase in fat level of breast muscle when compared to those fed the SBM based control diet $(p<0.05)$. Including dietary processed faba bean meal in guinea fowls increased the lightness of the breast $(p<0.05)$ meat, as depicted by higher $L^{*}$ values. Breast meat color $\left(a^{*}\right.$ and $\left.b^{*}\right)$ was not influenced by dietary treatment. The WHC of breast meat of guinea fowl broilers fed the faba bean meal was about 2.5\% higher than those fed the SBM based diets $(\mathrm{p}<0.05)$.

The influence of diets on the total lipids and phospholipids as well as cholesterol levels of breast meat of guinea fowls is presented in Table 4. Total lipids and phospholipids level in breast meat from birds fed the dehulled-micronized faba bean diet were higher than those of control SBM diet $(\mathrm{p}<0.05$ and $\mathrm{p}<0.01$, respectively). Moreover, breast meat of guinea fowls on the dehulledmicronized based diet exhibited lower cholesterol content when compared to birds fed the control treatment $(\mathrm{p}<0.05)$.

The FA compositions of breast meat of guinea fowl broilers fed the SBM control and the dehulled-micronized faba bean diets are reported in Table 5. The FA profiles of the breast muscle of guinea fowl broilers fed the faba bean diet showed a lower fraction of total saturated FA (SFA) $(p<0.01)$ when compared to birds fed a diet containing SBM. On the other hand, the percentage of total polyunsaturated FA (PUFA) was about $7 \%$ higher $(p<0.05)$ in meats from guinea fowl broilers fed the dehulledmicronized based diet, particularly docosapentaenoic (DPA). The percent DPA in breast muscle of birds on the faba bean diet was about $24.5 \%$ higher than that of birds fed the SBM based diet $(p<0.05)$. The differences in the ratio of saturated to unsaturated FAs $(\mathrm{S} / \mathrm{P})$ were not different; however, the percent content of $n-6$ PUFA in breast muscle of guinea fowl broilers fed dehulled-micronized faba bean diet was higher $(\mathrm{p}<0.01)$ than that those fed the SBM. The $n-6$ to $n-3$ ratio $(n-6 / n-3)$ was numerically lower $(p=0.061)$ in birds on faba bean based diet than birds on SBM-based diet, an indication that breast muscle of guinea fowl broilers fed the processed legumes exhibited a numerically higher ( $\mathrm{p}=$ 0.059 ) content of the n-3 FA than those on SBM diet.

The AI and TI of breast meat were significantly reduced $(p<0.05)$ when guinea fowl broilers fed treated faba bean in diet. Moreover, the $\mathrm{HH}$ ratio was improved in meat from

Table 4. Effect of dietary protein source on total of lipids, phospholipids and cholesterol contents in breast meat (Pectoralis major) from guinea fowl broilers

\begin{tabular}{lcccc}
\hline \multirow{2}{*}{ Item } & \multicolumn{4}{c}{ Diet } \\
\cline { 2 - 5 } & Soybean & Faba bean & SEM & p-value \\
\hline Total lipids $(\mathrm{g} / \mathrm{kg})$ & 0.18 & 0.21 & 0.037 & $<0.05$ \\
Total phospholipids $(\mathrm{mg} / \mathrm{g})$ & 4.25 & 5.15 & 0.189 & $<0.01$ \\
Total cholesterol $(\mathrm{mg} / \mathrm{g})$ & 0.41 & 0.30 & 0.022 & $<0.05$ \\
\hline
\end{tabular}

SEM, standard error of the mean.
Table 5. Effect of dietary protein source on the fatty acid composition ( $\%$ of total FA) of breast meat (Pectoralis major) from guinea fowl broilers at 12 weeks of age

\begin{tabular}{|c|c|c|c|c|}
\hline \multirow{2}{*}{ Item } & \multicolumn{4}{|c|}{ Diet } \\
\hline & Soybean & Faba bean & SEM & p-value \\
\hline C12:0 Lauric & 1.22 & 1.01 & 0.11 & 0.099 \\
\hline C14:0 Myristic & 4.34 & 4.09 & 0.20 & 0.071 \\
\hline C16:0 Palmitic & 20.51 & 18.47 & 0.27 & $<0.05$ \\
\hline C18:0 Stearic & 0.71 & 0.39 & 0.10 & $<0.05$ \\
\hline C14:1 n-5 Myristoleic & 0.42 & 0.45 & 0.09 & 0.123 \\
\hline C16:1 n-7 Palmitoleic & 4.62 & 4.90 & 0.13 & 0.202 \\
\hline C18:1 n-9 Oleic & 35.26 & 35.41 & 0.29 & 0.080 \\
\hline C18:2 n-6 Linoleic & 28.42 & 30.27 & 0.31 & $<0.01$ \\
\hline C18:3 n-3 $\alpha$-Linolenic & 0.27 & 0.46 & 0.06 & $<0.05$ \\
\hline C18:3 n-6 $\gamma$-Linolenic & 0.55 & 0.60 & 0.08 & 0.103 \\
\hline C20:4 n-6 Arachidonic & 0.79 & 0.94 & 0.07 & $<0.05$ \\
\hline C20:5 n-3 EPA & 1.34 & 1.29 & 0.11 & 0.188 \\
\hline C22:5 n-3 DPA & 0.98 & 1.22 & 0.15 & $<0.05$ \\
\hline C22:6 n-3 DHA & 0.57 & 0.50 & 0.09 & 0.092 \\
\hline$\Sigma$ SFA & 26.78 & 23.96 & 0.21 & $<0.01$ \\
\hline$\Sigma$ MUFA & 40.30 & 40.76 & 0.14 & $<0.05$ \\
\hline$\Sigma$ PUFA & 32.92 & 35.28 & 0.42 & $<0.05$ \\
\hline$\Sigma$ PUFA n-6 & 29.76 & 31.81 & 0.29 & $<0.01$ \\
\hline$\Sigma$ PUFA n-3 & 3.16 & 3.47 & 0.17 & 0.059 \\
\hline$n-6 / n-3^{1}$ & 9.42 & 9.17 & 0.31 & 0.061 \\
\hline $\mathrm{S} / \mathrm{P}^{2}$ & 0.37 & 0.32 & 0.04 & 0.156 \\
\hline Atherogenic index & 0.53 & 0.47 & 0.03 & $<0.05$ \\
\hline Thrombogenic index & 0.57 & 0.49 & 0.04 & $<0.05$ \\
\hline $\mathrm{HH}^{3}$ & 2.72 & 3.11 & 0.07 & $<0.05$ \\
\hline
\end{tabular}

FA, fatty acid; SEM, standard error of the mean; EPA, eicosapentaenoic acid; DPA, docosapentaenoic acid; DHA, docosahexaenoic acid; SFA, saturated fatty acid; MUFA, monounsaturated fatty acid; PUFA, polyunsaturated fatty acid.

${ }^{1}$ n-6/n-3, PUFA n-6/PUFA n-3 ratio.

${ }^{2} \mathrm{~S} / \mathrm{P}$, saturated fatty acid/unsaturated fatty acid.

${ }^{3} \mathrm{HH}$, hypocholesterolaemic/hypercholesterolaemic ratio.

birds fed faba bean-based diet than those in control diet (3.11 vs 2.72, respectively; $\mathrm{p}<0.05$ ). Thus, these results suggest that the dehulled-micronized faba bean-based diet may contain more hypocholesterolaemic properties than the SBM control diet.

\section{DISCUSSION}

Dietary dehulled-micronized faba bean inclusion in guinea fowls ration and the effects on their growth traits and meat quality which would include functional food properties, such as the content of n-3 and n-6 FA, have not been investigated. Thus, cross-referencing in discussion of findings in this study will be based on available data from other poultry species such as chickens or turkeys. The adequate growth performance of guinea fowl broilers fed a diet containing dehulled-micronized faba bean meal was consistent with previous reports conducted on broiler 
chickens by Laudadio et al. (2011) and Usayran et al. (2014). On the other hand, Dal Bosco et al. (2013) reported lower growth rate and feed efficiency in broiler chickens fed diets containing 16\% extruded faba bean. In their study, the authors stated that the negative effect of the faba bean on birds' performance could be ascribed to various reasons: lower level of some essential amino acids and the presence of vicine, convicine and tannins as anti-nutritional factors. However, the variations in the formulation of the experimental diets and the level of inclusion of faba bean meal in poultry diets appear to be the main cause of inconsistencies in performance among available literature.

In our study, no differences were reported for dressing percentage and contents of major muscles (breast, drumstick, and thigh) in guinea fowl broiler carcasses fed diet with and without dehulled-micronized faba bean meal. In a recent study, Laudadio et al. (2011) evaluated in broiler chickens the effect of diet containing $31 \%$ processed faba bean substituting SBM. In this report, the weight of breast muscle portion of guinea fowl carcass fed faba bean meal correspond to the average breast muscle weight of the French guinea fowl reported earlier in Nahashon et al. (2005) and Laudadio et al. (2012) in Pearl Grey guinea fowl. Similar to birds fed the SBM-based diet, the optimum productive performance when fed the faba bean diet is in part attributed to a well-balanced amino acid profile coupled with the supplementation of lysine, methionine and threonine. In fact, the dietary inadequacy and balance of amino acids is well known to be the main reason of diminished content of breast muscle in poultry carcasses. Despite the abdominal fat content of guinea fowl broilers being reduced when SBM was replaced with pea meal in diet, the abdominal fat content of the birds expressed as percent of BW at slaughter was lower than that reported earlier in broiler chickens (Laudadio and Tufarelli, 2011). This experiment and other studies have demonstrated that the guinea fowl broilers tend to deposit less abdominal fat and have leaner carcasses than broiler chickens (Nahashon et al., 2005; Laudadio et al., 2012).

The content of moisture, protein and ash in breast meat of guinea fowl broilers in our study was consistent with previous reports where chickens (Laudadio et al., 2011; Dal Bosco et al., 2013) were fed faba bean based diets. The meat color indexes of guinea fowls were influenced by the dietary substitution of SBM for dehulled-micronized faba bean meal. As well known, meat color is a valuable indicator of quality and one of the first characteristics noted by consumers, especially in boneless products. Inclusion of the faba bean meal in the diet led to higher values of lightness in breast meat. These values were in the optimal range, and therefore these muscles would not be considered to be dark (Woelfel et al., 2002). Our findings are consistent with previous report by Laudadio et al. (2012) in guinea fowls fed processed legume seeds, and may be explained, in part, by higher lipid content in these muscles which may also contain less lipid-soluble pigments such as xanthophylls.

Meat total lipid content contributes to both the flavor and, most importantly, the nutrient composition of poultry. Phospholipids are essential components of cell membranes and have a fundamental role in their function and structure. A significant amount of studies have demonstrated that phospholipids have different health functions: such as enhancing memory performance of the ageing brain, preventing atherosclerosis, inflammation and hyperlipidaemia (Tian et al., 2011). In the present study, the higher concentrations of phospholipids found in the muscle of birds fed the faba bean diet when compared to SBMcontrol diet was almost certainly a reflection of the higher total lipid or fat content of guinea fowl broilers on the faba bean diet, as a result of the improved fatness of their meat. The level of cholesterol in poultry meat is one of the most important qualitative parameters and its concentrations in meat can be efficiently modified by diet (Dhama et al., 2015). In the present study, the breast meat of guinea fowls fed a treated faba bean based diet contained a lower level of cholesterol than those fed the SBM-control diet, which may be attributed to the difference in feed composition. The dehulled-micronized faba bean diet may include biologically active compounds able to influence the cholesterol metabolism in birds and in altering the meat cholesterol level in poultry species as well as in guinea fowl.

Feeding guinea fowl broilers with dehulled-micronized faba bean resulted in a reduction of total SFA and in increased PUFA. The production of meat containing high levels of PUFA is of considerable interest, because of PUFA are considered as functional ingredients capable of reducing the incidence of coronary heart disease and other chronic diseases in humans (Peiretti et al., 2007; Laudadio et al., 2015). The inclusion of faba bean in guinea fowl broilers diet was associated with a diminishing level of palmitic (C16:0) and stearic (C18:0) acids. These SFA are well known for their outstanding hypercholesterolemic properties that have been implicated in elevating cholesterol levels in blood serum and meat (Baggio et al., 2002). It was noted that irrespective of dietary treatments, guinea fowls tend to have a higher content of n-3 FA than broiler chickens when fed dehulled-micronized faba bean as reported by Laudadio et al. (2011). However, the greatest contribution to muscle fat of guinea fowls fed the faba bean diet, even irrespective of the dietary composition, was the levels of linoleic (C18:2 n-6), linolenic (C18:3 n-3) and arachidonic (C20:4 n-6) acids. In our study, the increase in PUFA observed in guinea fowls fed the faba bean-based 
diet revealed that dehulled-micronized faba bean could replace conventional protein sources, such as SBM, in guinea fowls nutrition without negatively affecting their productive performance and meat quality. Supplementing dehulled-micronized faba bean in diet improved atherogenic and thrombogenic indexes as well as the $\mathrm{HH}$ ratio of guinea fowl meat. These observations indicate that the dietary dehulled-micronized faba bean inclusion can enrich these animal proteins with functional food properties providing healthy balanced diets that are useful to prevent human diseases. Similar observations were also noted in other meat-type species such as chickens (Dal Bosco et al., 2013) and rabbits (Peiretti et al., 2007).

In conclusion, our feeding trial demonstrated that the total replacement of SBM with dehulled-micronized faba bean meal in guinea fowl diet had no negative effect on growth performance and carcass yield. Moreover, dietary inclusion of faba bean meal enriched guinea fowl meat with PUFA, thereby improving their nutritional value and offering a valid alternative way for enhancing the quality and marketability of guinea fowl-meat.

\section{CONFLICT OF INTEREST}

We certify that there is no conflict of interest with any financial organization regarding the material discussed in the manuscript.

\section{REFERENCES}

AOAC. 2000. Official Methods of Analysis. 17th edn. Association of Official Analytical Chemists, Gaithersburg, MD, USA.

Baggio, S. R., E. Vicente, and N. Bragagnolo. 2002. Cholesterol oxides, cholesterol, total lipid, and fatty acid composition in turkey meat. J. Agric. Food Chem. 50:5981-5986.

Bartlett, G. R. 1959. Phosphorus assay in column chromatography. J. Biol. Chem. 234:466-468.

Combes, S., I. González, S. Déjean, A. Baccini, N. Jehl, H. Juin, L. Cauquil, B. Gabinaud, F. Lebas, and C. Larzul. 2008. Relationships between sensory and physicochemical measurements in meat of rabbit from three different breeding systems using canonical correlation analysis. Meat Sci. 80:835-841.

Dal Bosco, A., S. Ruggeri, S. Mattioli, C. Mugnai, F. Sirri, and C. Castellini. 2013. Effect of faba bean Vicia Faba var. minor) inclusion in starter and growing diet on performance, carcass and meat characteristics of organic slow-growing chickens. Ital. J. Anim. Sci. 12:472-478.

Dhama, K., S. K. Latheef, S. Mani, H. A. Samad, K. Karthik, R. Tiwari, R. U. Khan, M. Alagawany, M. R. Farag, G. M. Alam, V. Laudadio, and V. Tufarelli. 2015. Multiple beneficial applications and modes of action of herbs in poultry health and production: A review. Int. J. Pharmacol. 11:152-176.

Diaz, D., M. Morlacchini, F. Masoero, M. Moschini, G. Fusconi, and G. Piva. 2006. Pea seeds (Pisum sativum), faba beans
(Vicia fabavar. minor) and lupin seeds (Lupinus albus var. multitalia) as protein sources in broiler diets: effect of extrusion on growth performance. Ital. J. Anim. Sci. 5:43-53.

Folch, J., M. Lees, and G. H. Sloane-Stanley. 1957. A simple method for the isolation and purification of total lipides from animal tissues. J. Biol. Chem. 226:497-507.

Fru-Nji, F., E. Niess, and E. Pfeffer. 2007. Effect of graded replacement of soybean meal by faba beans (Vicia faba L.) or field peas (Pisum sativum L.) in rations for laying hens on egg production and quality. J. Poult. Sci. 44:34-41.

Kauffman, R. G., G. Eikelenboom, P. G. van der Wal, G. Merkus, and M. Zaar. 1986. The use of filter paper to estimate drip loss of porcine musculature. Meat Sci. 18:191-200.

Khan, R. U., Z. Nikousefat, V. Tufarelli, S. Naz, M. Javdani, and V. Laudadio. 2012. Garlic (Allium sativum) supplementation in poultry diets: Effect on production and physiology. World's Poult. Sci. J. 68:417-424.

Khattab, R. Y., S. D. Arntfield, and C. M. Nyachoti. 2009. Nutritional quality of legume seeds as affected by some physical treatments, Part 1: Protein quality evaluation. LWTFood Sci. Technol. 42:1107-1112.

Larbier, M. and B. Leclercq. 1994. Nutrition and feeding of poultry. Nottingham University Press, Nottingham, UK.

Laudadio, V. and V. Tufarelli. 2011. Pea (Pisum sativum L.) seeds as an alternative dietary protein source for broilers: Influence on fatty acid composition, lipid and protein oxidation of dark and white meats. J. Am. Oil Chem. Soc. 88:967-973.

Laudadio, V. and V. Tufarelli. 2012. Effect of treated field pea (Pisum sativum L. cv Spirale) as substitute for soybean extracted meal in a wheat middlings-based diet on egg production and quality of early laying brown hens. Arch. Geflügelk. 76:1-5.

Laudadio, V., E. Ceci, and V. Tufarelli. 2011. Productive traits and meat fatty acid profile of broiler chickens fed diets containing micronized fava beans (Vicia faba L. var. minor) as the main protein source. J. Appl. Poult. Res. 20:12-20.

Laudadio, V., E. Ceci, N. M. B. Lastella, and V. Tufarelli. 2015. Dietary high-polyphenols extra-virgin olive oil is effective in reducing cholesterol content in eggs. Lipids Health Dis. 14:1-7.

Laudadio, V., S. N. Nahashon, and V. Tufarelli. 2012. Growth performance and carcass characteristics of guinea fowl broilers fed micronized-dehulled pea (Pisum sativum L.) as a substitute for soybean meal. Poult. Sci. 91:2988-2996.

Laudadio, V., V. Tufarelli, M. Dario, F. P. D'Emilio, and A. Vicenti. 2009. Growth performance and carcass characteristics of female turkeys as affected by feeding programs. Poult. Sci. 88:805-810.

Medugu, C. I., A. O. Raji, J. U. Igwebuike, and E. Barwa. 2011. Alternative cereal grains and cereal by-products as sources of energy in poultry diets- A review. Res. Opin. Anim. Vet. Sci. 1:530-542.

Nahashon, S. N., N. Adefope, A. Amenyenu, and D. Wright. 2005. Effects of dietary metabolizable energy and crude protein concentrations on growth performance and carcass characteristics of French guinea broilers. Poult. Sci. 84:337344.

Peiretti, P. G., P. P. Mussa, L. Prola, and G. Meineri. 2007. Use of different levels of false flax (Camelina sativa L.) seed in diets 
for fattening rabbits. Livest. Sci. 107:192-198.

Puvača, N., D. Lukač, D. Ljubojević, V. Stanaćev, M. Beuković, Lj. Kostadinović, and N. Plavša. 2014. Fatty acid composition and regression prediction of fatty acid concentration in edible chicken tissues. World's Poult. Sci. J. 70:585-592.

Santos-Silva, J., R. J. B. Bessa, and F. Santos-Silva. 2002. Effect of genotype, feeding system and slaughter weight on the quality of light lambs: II. Fatty acid composition of meat. Livest. Prod. Sci. 77:187-194.

SAS Institute Inc. 2004. SAS/STAT User's Guide, Release 8.1. Statistical Analysis System. SAS Institute Inc. Cary, NC, USA.

Sperry, W. M. and M. Webb. 1950. A revision of the Schoenheimer-Sperry method for cholesterol determination. J. Biol. Chem. 187:97-106.

Sukhija, P. S. and D. L. Palmquist. 1988. Rapid method for determination of total fatty acid content and composition of feedstuffs and feces. J. Agric. Food Chem. 36:1202-1206.

Sun, Y. M. and M. Luo. 1993. Livestock and Poultry Meat Science. Shandong Science and Technology Press, Jinan, China. pp. 1318.
Tian, Y., S. Zhu, M. Xie, W. Wang, H. Wu, and D. Gong. 2011. Composition of fatty acids in the muscle of black-bone silky chicken (Gallus gellus demesticus brissen) and its bioactivity in mice. Food Chem. 126:479-483.

Tufarelli, V., M. Dario, and V. Laudadio. 2007. Effect of xylanase supplementation and particle-size on performance of guinea fowl broilers fed wheat-based diets. Int. J. Poult. Sci. 6:302307.

Ulbricht, T. L. V. and D. A. T. Southgate. 1991. Coronary heart disease: Seven dietary factors. Lancet 338:985-992.

Usayran, N. N., H. Sha'ar, G. W. Barbour, S. K. Yau, F. Maalouf, and M. T. Farran. 2014. Nutritional value, performance, carcass quality, visceral organ size, and blood clinical chemistry of broiler chicks fed $30 \%$ tannin-free fava bean diets. Poult. Sci. 93:2018-2027.

Woelfel, R. L., C. M. Owens, E. M. Hirschler, R. MartinezDawson, and A. R. Sams. 2002. The characterization and incidence of pale, soft, and exudative broiler meat in a commercial processing plant. Poult. Sci. 81:579-584. 